\title{
Editorial
}

\section{Urban Water Management: A Pragmatic Approach}

\author{
Bruno Brunone ${ }^{1, *(\mathbb{D})}$ and Marco Franchini ${ }^{2}$ D \\ 1 Department of Civil and Environmental Engineering, The University of Perugia, Via G. Duranti, \\ 93-06125 Perugia, Italy \\ 2 Engineering Department, The University of Ferrara, Via Saragat, 1-44122 Ferrara, Italy; frnmrc@unife.it \\ * Correspondence: bruno.brunone@unipg.it; Tel.: +39-075-5853617
}

Received: 15 December 2020; Accepted: 17 December 2020; Published: 21 December 2020

When the 4th edition of the International Electronic Conference on Water Sciences (ECWS-4), sponsored by Water and MDPI, was launched, the COVID-19 pandemic did not exist at all. No one would have imagined the terrifying waves of the pandemic, with the associated upheaval of life, millions of people infected, and so many deaths throughout the world; nor the dramatic economic and social crises and the spasmodic expectation of the vaccine; nor the fact that almost all events would have to be cancelled or taken not in person but through the web! A change of mentality happened, and our lives changed completely. As a result, distance learning, webinars, and electronic conferences became the rule.

Apart from the above pandemic-related considerations-which may (hopefully) pass in the next months-this Editorial is the final act of ECWS-4, since it presents the ten papers from the Conference included in the Water Special Issue titled "Urban Water Management: A Pragmatic Approach". This is not an easy task. In fact, as reported in the message from the Guest Editors:

... the extremely diverse topics of ECWS-4 range from natural water resources management to water treatments, from high-tech pipe systems to storm and combined sewers, and all refer to the theme of urban hydraulics and hydrology. This Special Issue constitutes a tremendous chance to contribute to a comprehensive (and quite concise) textbook. In fact, the urgent need to refine reliable and sustainable tools for the management of the natural resources in the present scenario dominated by climate change is apparent to all.

The extreme diversity of the published papers reflects the diversity and complexity of the problems deriving from the everyday management of urban water. An effective representation of such a diversity/complexity is given by Macaulay [1] (Figure 1), who compared it to a labyrinth (from the pre-Greek $\lambda \alpha \beta v \rho \imath v \theta o \varsigma$ : labrys (meaning "the double ax") and the suffix "into" (meaning "place"), combine to form the meaning "the double ax building"). The Knossos labyrinth "like the Acropolis, Stonehenge, or the Pyramids, stands powerfully for an entire ancient culture" [2]. 


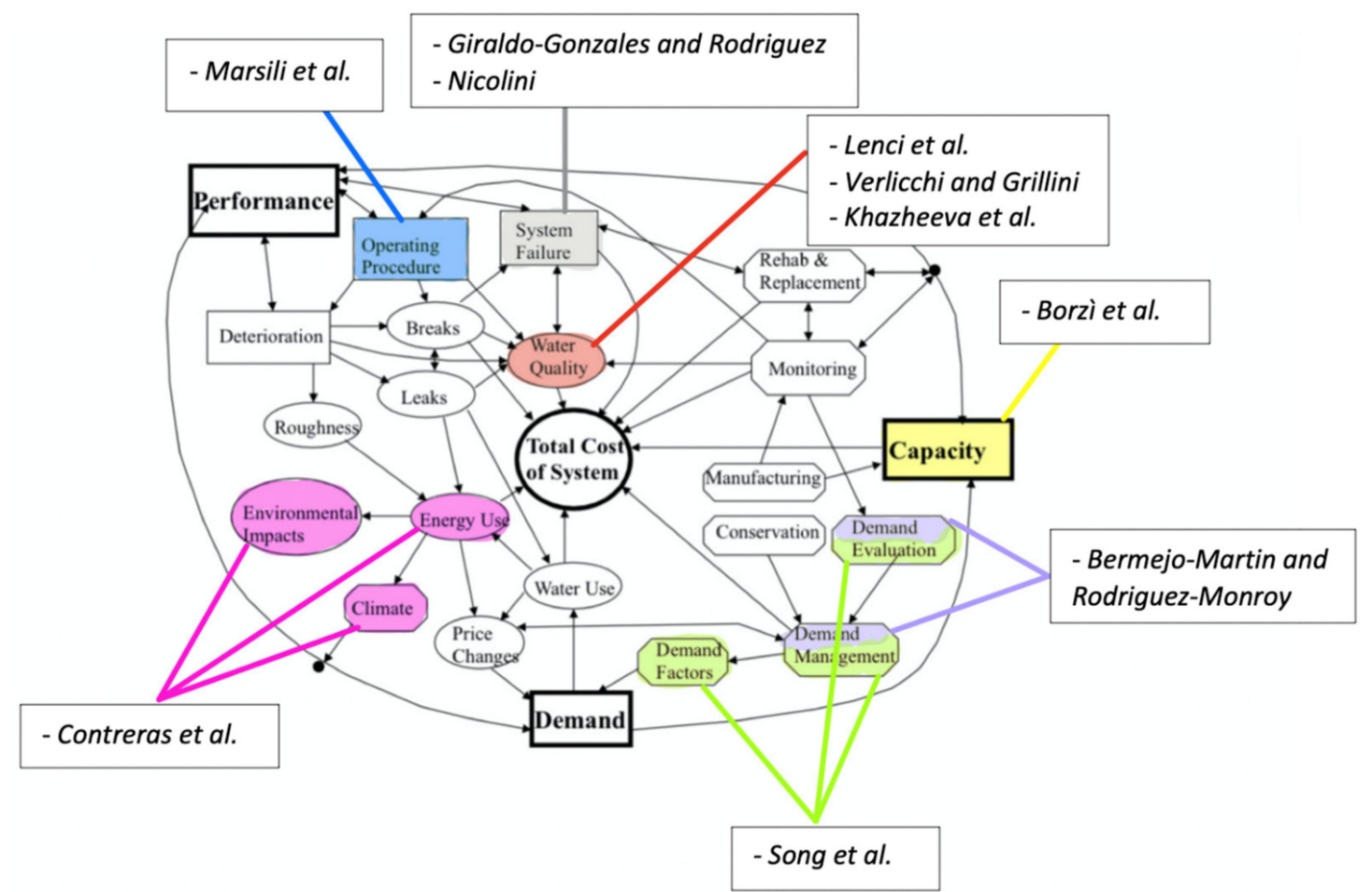

Figure 1. The labyrinth of the Urban Water Systems (modified from [1]).

However, since the origins of the labyrinth are much more ancient than the Minoan myth, we speak in terms of the labyrinth "before" the labyrinth [3]. In fact, it comes from the travel of Gilgamesh, King of Uruk, toward the mountains in the country of Huwawa, the monstrous man/tree. In his travel of loss and fear, which was prompted by an escape from pestilence (!), when Gilgamesh cuts the primordial tree (he had never seen a tree in the flat Mesopotamia where he used to live), he discovers its growth circles, which remind him of the bowels or a coiled snake (consider the bowel-shaped face of Huwawa). Initially, the primordial shape of the labyrinth was dominated by curved lines, which will later become straight lines in the next centuries, as in the beautiful labyrinth in the Marco Lucrezio's House in Pompeii, Italy (Figure 2). However, the crucial part of the labyrinth is its center, which can be compared to the truth-the truth that man reaches only after a very perilous travel against adversities. Or, in other words, the enigma that man solves only after many attempts. As much like running inside a labyrinth, during his life man can lose his way.

Going back to water distribution networks (WDNs) and the other urban water systems, what is the link with the labyrinth? What is the element corresponding to the center/enigma of the labyrinth? The link is the mentioned complexity of WDNs and urban water systems, and the center/enigma is its "optimal management". How can such optimal management be achieved? As is suggested in the famous labyrinth painted on the ceiling of the ducal palace of Mantua (Italy), the solution to the problem of the uncertainties of life (i.e., to reach the center of the labyrinth and then to exit the labyrinth or not) "Forse che sì forse che no" ("maybe yes maybe no") is "Dedalee industrie et Teseie virtutis" ("by means of Daedalus' sagacity and Theseus' worth), which in the context of WDNs and urban water systems means "by using a pragmatic approach". 


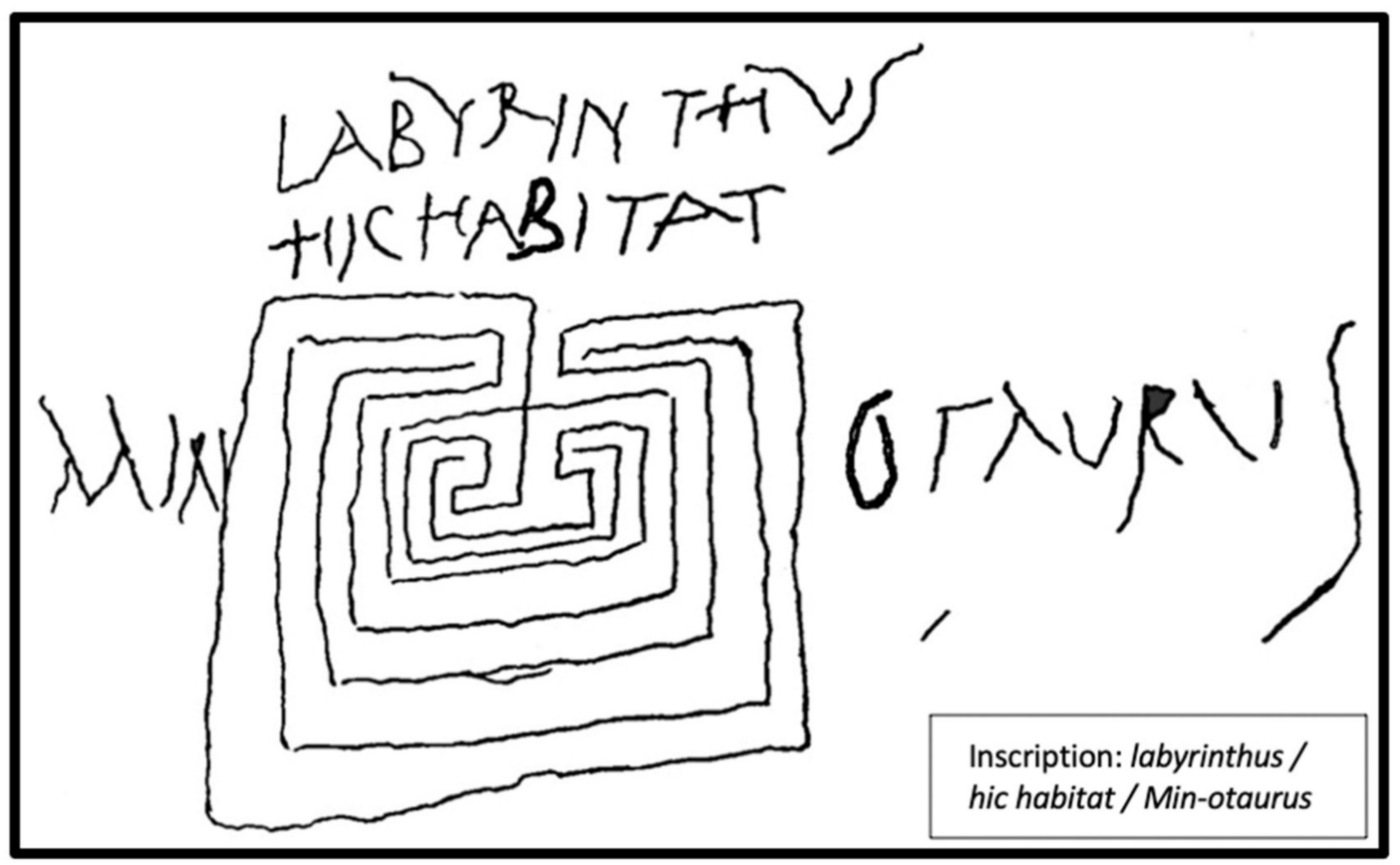

Figure 2. Labyrinth from the Marco Lucrezio's House in Pompeii, Italy (courtesy of Recuperando Srl, Forte dei Marmi, Italy-www.recuperando.com).

This special issue consists of 10 papers that cover a wide range of research topics related to urban water systems. The specific topics include (Figure 1): operating procedure [4], system failure [5,6], water quality [7-9], capacity [10], demand [11,12], and energy and climate [13].

Marsili et al. [4] offer the results of laboratory tests on the behavior of a piston-actuated pressure reducing valve when low flow conditions occur. Particularly, attention is focused on evaluating the stabilization time intervals needed to reach the imposed value of the downstream pressure.

In Giraldo-González and Rodríguez [5] several statistical and machine learning models are analyzed with the aim of selecting a suitable pipe failure model for the management of WDNs by considering the available information and network characteristics. The performance of the considered models is checked for a WDN in Bogotá (Colombia).

In Nicolini [6], a complex networks theory-based methodology for evaluating a synthetic vulnerability index for comparing the robustness of different WDNs with regard to the number of nodes where a contaminant could be accidentally injected is proposed. In the paper the possible causes of the contamination events are pointed out: transients giving rise to negative pressure, and rehabilitation work requiring the temporary isolation and emptying of a certain number of pipes.

The paper by Verlicchi and Grillini [7] concerns the water quality with particular regard to the range of concentration of both macropollutants and micropollutants of surface water and groundwater in the Republic of South Africa and Mozambique. With the aim of improving the quality of source water for drinking needs, recommendations on water treatment selection are provided.

A contribution of interest for applications linked to subsurface contamination and remediation is offered by Lenci et al. [8], who analyze the non-Newtonian fluid flow in fractured media.

The role of the characteristics of the inflowing tributary and mine water on the chemical composition of the water of river Modonkul (Russia) and the environment is evaluated in Khazheeva et al. [9]. The analysis is based on the results of an extended field measurement campaign.

In the study by Borzì et al. [10], hydrologic processes are investigated over a long period of time, including both wet and dry conditions, with the aim of estimating the effect of evapotranspiration in water resources assessment with particular attention on groundwater resource quantification. The refined digital elevation model-based inverse hydrogeological balance method is applied to the Alcantara river basin in Sicily (Italy). 
In the paper by Bermejo-Martín and Rodríguez-Monroy [11], a procedure in which design thinking (DT) methodologies are used, is proposed in order to achieve a more efficient use of urban water for the city of Huelva (Spain). The iterative process based on DT allows for the inclusion of citizens in the definition of a rational and sustainable use of water.

The performance of the pivotal modeling methods for generating the optimal allocation scheme of a multi-source water supply system with a possible joint operation of water quality and quantity is checked in the paper by Song et al. [12]. The case study of the city of Tianjin (China) is discussed as a representative case of the present dynamics of water demand.

The effect of the variability in precipitation and snow cover on the energy production of river hydropower systems is examined in the study by Contreras et al. [13]. The results of the analysis executed for a pilot system located in a Spanish semi-arid Mediterranean area, where seasonal forecasting is quite challenging, highlight the importance of the seasonal climate forecast information.

To conclude, a possible theme for a future Special Issue and/or a conference could be "what do we know about the global hydrologic urban cycle and the most appropriate layout of its infrastructures?" and then "how can we check them and their internal relationships?". These topics cover a wide range of research fields that need to be interconnected and represent an imperative challenge for the scientific community.

Author Contributions: The two authors made fairly equal contributions to this editorial. All authors have read and agreed to the published version of the manuscript.

Funding: This research received no external funding.

Acknowledgments: The authors thank a lot Lucio Fiorini of the University of Perugia for the intriguing discussion about the myth of the labyrinth.

Conflicts of Interest: The authors declare no conflict of interest.

\section{References}

1. Macaulay, D. Underground; Houghton Miffin Company: Boston, MA, USA, 1976.

2. Casteleden, R. The Knossos Labyrinth: A New View of the "Palace of Minos" at Knossos; Routledge: London, UK, 1990.

3. Silvestri, D. The "labirithm" before the labirithm. In The Dizziness of the Labyrinth; Aragona, R., Ed.; Edizioni Scientifiche Italiane: Napoli, Italy, 2000. (In Italian)

4. Marsili, V.; Zarbo, R.; Alvisi, S.; Franchini, M. Laboratory analysis of a piston-actuated pressure-reducing valve under low flow conditions. Water 2020, 12, 940. [CrossRef]

5. Giraldo-González, M.; Rodríguez, J. Comparison of statistical and machine learning models for pipe failure modeling in water distribution networks. Water 2020, 12, 1153. [CrossRef]

6. Nicolini, M. Complex networks theory for evaluating scaling laws and WDS vulnerability for potential contamination events. Water 2020, 12, 1296. [CrossRef]

7. Verlicchi, P.; Grillini, V. Surface water and groundwater quality in South Africa and Mozambique-Analysis of the most critical pollutants for drinking purposes and challenges in water treatment selection. Water 2020, 12, 305. [CrossRef]

8. Lenci, A.; Longo, S.; Di Federico, V. Shear-thinning fluid flow in variable-aperture channels. Water 2020, 12, 1152. [CrossRef]

9. Khazheeva, Z.; Plyusnin, A.; Smirnova, O.; Peryazeva, E.; Zhambalova, D.; Doroshkevich, S.; Dabaeva, V. Mining activities and the chemical composition of R. Modonkul, Transbaikalia. Water 2020, 12, 979. [CrossRef]

10. Borzì, I.; Bonaccorso, B.; Aronica, G. The role of DEM resolution and evapotranspiration assessment in modeling groundwater resources estimation: A case study in Sicily. Water 2020, 12, 2980. [CrossRef]

11. Bermejo-Martín, G.; Rodríguez-Monroy, C. Design thinking methodology to achieve household engagement in urban water sustainability in the City of Huelva (Andalusia). Water 2020, 12, 1943. [CrossRef]

12. Song, P.; Wang, C.; Zhang, W.; Liu, W.; Sun, J.; Wang, X.; Lei, X.; Wang, H. Urban multi-source water supply in China: Variation tendency, modeling methods and challenges. Water 2020, 12, 1199. [CrossRef] 
13. Contreras, E.; Herrero, J.; Crochemore, L.; Aguilar, C.; Polo, M. Seasonal climate forecast skill assessment for the management of water resources in a run of river hydropower system in the Poqueira River (Southern Spain). Water 2020, 12, 2119. [CrossRef]

Publisher's Note: MDPI stays neutral with regard to jurisdictional claims in published maps and institutional affiliations.

(C) 2020 by the authors. Licensee MDPI, Basel, Switzerland. This article is an open access article distributed under the terms and conditions of the Creative Commons Attribution (CC BY) license (http://creativecommons.org/licenses/by/4.0/). 